\title{
Detection of late arrhythmia and conduction disturbance after correction of tetralogy of Fallot
}

\author{
JOHN E DEANFIELD, WILLIAM J MCKENNA, \\ KATHERINE A HALLIDIE-SMITH
}

From the Division of Cardiovascular Disease, Royal Postgraduate Medical School, Du Cane Road, London

SUMMARY The electrocardiographic conduction disturbances were evaluated retrospectively, in relation to prognosis, in 196 patients who underwent correction of tetralogy of Fallot. The follow-up was one to 20 years (mean 10). After surgery complete right bundle-branch block occurred in 187 patients $(95 \%)$, right bundle-branch block and left axis deviation in 17 patients $(9 \%)$, and progressive conduction defects, either left axis deviation or right bundle-branch block, developed during follow-up in 21 patients $(11 \%)$. Nine patients $(4.6 \%)$ died suddenly and two patients developed complete heart block late after the operation. Though late sudden death or complete heart block occurred in 19 per cent of patients with progressive conduction defects as opposed to 4 per cent of the group with stable conduction defects, the difference was not significant.

Twenty-four hour ambulatory electrocardiographic monitoring was performed in 74 patients; 41 per cent had significant (Lown grade 2, 3, or 4) ventricular arrhythmias. The incidence of ventricular arrhythmia in the group with progressive conduction defects $(80 \%)$ was significantly higher than in the group with stable conduction defects $(30 \%)$. As occult arrhythmia may be the cause of sudden death, it is important to identify these patients.

Late sudden death has been reported after surgical correction of tetralogy of Fallot in up to 3.4 per cent of patients. ${ }^{1}$ Both the cause of these deaths and the prognostic significance of preoperative and postoperative conduction disturbances remain controversial. Right bundle-branch block is the commonest conduction disturbance: Kulbertus et al. ${ }^{2}$ first described the occurrence of right bundle-branch block and left anterior hemiblock after correction of tetralogy of Fallot, and suggested that patients with this electrocardiographic finding might have a poor prognosis. Wolff et $a .^{3}{ }^{3}$ reported a significantly increased incidence of late complete heart block and sudden death in this group; others, however, have suggested a benign prognosis. ${ }^{45}$ Ventricular arrhythmias have also been reported after correction of tetralogy of Fallot and it has been suggested that they may lead to sudden death. ${ }^{16-8}$

The purpose of this study was to determine the nature and prevalence of arrhythmia after correction of tetralogy of Fallot. Retrospective analysis was also performed to correlate the arrhythmias detected with postoperative conduction disturbances.

Received for publication 4 February 1980

\section{Patients and methods}

The electrocardiograms of 196 consecutive patients, 114 male and 82 female, who underwent correction of tetralogy of Fallot at the Hammersmith Hospital between 1959 and 1971 were reviewed. Patients who died within one month of operation were excluded from the study. The age of patients at the time of corrective surgery was 3 to 20 years (mean 11). Thirty-eight patients $(19 \%)$ had previously undergone a Brock operation and 74 $(37 \%)$ had had a shunt procedure. The duration of follow-up was one to 20 years (mean 10).

The electrocardiograms were routine 12 lead tracings, and were recorded preoperatively (one to two days before surgery), postoperatively, and serially during the follow-up period. They were analysed for the presence of arrhythmias, conduction disturbances, and mean frontal QRS axis change. Right bundle-branch block was diagnosed when the QRS interval in the right praecordial leads exceeded 120 milliseconds with terminal conduction delay. Incomplete right bundle-branch block was defined as a QRS duration of less than 120 milliseconds with terminal conduction delay. Left axis deviation 
was considered present when the frontal plane $Q R S$ axis was between $-30^{\circ}$ and $-120^{\circ}$.

Preoperative and perioperative pulmonary artery, right ventricular, and left ventricular pressures were available in $180(92 \%)$ patients: 72 patients $(37 \%)$ underwent cardiac catheterisation in the follow-up period.

Twenty-four hour out-patient ambulatory electrocardiographic monitoring was performed on 74 patients using the Oxford Medilog cassette recording system. These patients were being followed up at the Hammersmith Hospital or other centres where ambulatory monitoring facilities were available. No other selection criteria were employed. The recordings were analysed by one of the authors using a Reynolds High Speed Pathfinder analyser and they were reviewed by a second physician. The ventricular arrhythmias found were graded using a modification of the Lown criteria. ${ }^{9}$ The following categories were defined: grade 0 , no ventricular extrasystoles in 24 hours; grade 1, occasional ventricular extrasystoles, but no more than 30 in any hour of monitoring; grade 2, more than 30 ventricular extrasystoles in any hour of monitoring; grade 3 , multiform ventricular extrasystoles; grade $4 \mathrm{a}$, couplets (two consecutive ventricular extrasystoles); grade $4 b$, ventricular tachycardia (three or more ventricular extrasystoles in succession).

\section{STATISTICAL ANALYSIS}

The Fisher exact test was used, where appropriate, to assess statistical significance.

\section{Results}

\section{ELECTROCARDIOGRAM}

Table 1 summarises the conduction patterns found on the preoperative, postoperative, and most recent follow-up electrocardiogram. Complete right bundle-branch block occurred in 95 per cent of patients after operation, and postoperative right

Table 1 Conduction defects on preoperative, postoperative, and follow-up electrocardiograms

\begin{tabular}{|c|c|c|c|c|c|}
\hline \multirow{2}{*}{ Conduction pattern } & \multirow{2}{*}{\multicolumn{2}{|c|}{$\begin{array}{l}\text { Preoperative } \\
\text { No. of } \\
\text { patients } \\
(\%)\end{array}$}} & \multirow{2}{*}{$\begin{array}{l}\text { Postoperative } \\
\text { No. of } \\
\text { patients } \\
(\%)\end{array}$} & \multirow{2}{*}{\multicolumn{2}{|c|}{$\begin{array}{l}\text { Follow-up } \\
\text { No. of } \\
\text { patients } \\
(\%)\end{array}$}} \\
\hline & & & & & \\
\hline $\begin{array}{l}\text { Normal } \\
\text { Incomplete RBBB } \\
\text { Complete RBBB } \\
\text { RBBB + LAD }\end{array}$ & $\begin{array}{r}170 \\
22 \\
4 \\
0\end{array}$ & $\begin{array}{l}(87) \\
(11) \\
(2) \\
(0)\end{array}$ & $\begin{aligned} 7 & (4) \\
2 & (1) \\
187 \star & (95) \\
17 & (9)\end{aligned}$ & $\begin{array}{r}2 \\
2 \\
192 \\
33\end{array}$ & $\begin{array}{l}(1) \\
(1) \\
(98) \\
(17)\end{array}$ \\
\hline
\end{tabular}

RBBB, right bundle-branch block; LAD, left axis deviation.

* Includes the 17 patients who also had left axis deviation. bundle-branch block and left axis deviation in 9 per cent of patients. During the follow-up period five patients $(2.5 \%)$ developed right bundle-branch block and 16 patients $(8 \%)$ developed progressive shift in QRS axis to left axis deviation. These late conduction defects occurred between six months and six years after operation. From the postoperative and follow-up electrocardiograms, three groups of patients were defined: (a) postoperative right bundle-branch block with normal axis or right axis deviation; (b) postoperative right bundlebranch block and left axis deviation; (c) progressive conduction defects, either progressive left axis shift or the development of right bundle-branch block during follow-up.

\section{POSTOPERATIVE ARRHYTHMIAS}

Table 2 summarises the perioperative arrhythmias detected in relation to the underlying electrocardiographic conduction defects. Perioperative transient complete heart block occurred in nine patients $(5 \%)$, one with postoperative right bundlebranch block and left axis deviation, and one with progressive left axis shift during follow-up.

\section{LATE ARRHYTHMIAS}

First degree atrioventricular block was seen in 20 patients $(10 \%)$ during follow-up. One of these patients had left axis deviation postoperatively and three had progressive late left axis deviation. Late complete heart block was uncommon, occurring in only two patients. Both of these patients had progressive late left axis deviation and one had had transient perioperative complete heart block. Ventricular extrasystoles were noted in 29 patients $(15 \%)$ on routine electrocardiograms.

\section{MORTALITY}

Fifteen patients died during the follow-up period. Four of the deaths were a result of infective endocarditis and two patients died at reoperation. Sudden death during follow-up, from documented or suspected arrhythmia, occurred in nine patients $(4.6 \%)$. The interval between surgery and death was two to 15 years (mean 5.5). Five of the patients who died suddenly were asymptomatic, while three had complained of syncopal episodes, and one of palpitation. None of these patients had undergone ambulatory electrocardiographic monitoring. Their conduction defects and arrhythmia documentation are shown in Table 3. Postoperatively, eight patients had right bundle-branch block and one patient had additional left axis deviation. During follow-up, there was progressive change in the electrocardiogram in two patients, one developing 
Table 2 Frequency of perioperative arrhythmias related to electrocardiographic conduction defects

\begin{tabular}{|c|c|c|c|c|c|c|c|c|c|}
\hline \multirow{2}{*}{$\begin{array}{l}\text { Conduction defect } \\
\text { Total group } \\
\text { RBBB }\end{array}$} & \multirow{2}{*}{$\begin{array}{l}\begin{array}{l}\text { Total } \\
\text { patients }\end{array} \\
196\end{array}$} & \multicolumn{2}{|c|}{$\begin{array}{l}\text { First degree } \\
A V \text { block }\end{array}$} & \multicolumn{2}{|c|}{$\begin{array}{l}\text { Complete heart } \\
\text { block }\end{array}$} & \multicolumn{2}{|c|}{ Nodal rhythm } & \multicolumn{2}{|c|}{$\begin{array}{l}\text { Ventricular } \\
\text { extrasystoles }\end{array}$} \\
\hline & & 18 & $(9 \%)$ & 9 & $(5 \%)$ & 10 & $(5 \%)$ & 21 & $(11 \%)$ \\
\hline $\mathbf{R B B B}+\mathbf{L A D}$ & 17 & 4 & $(23 \%)$ & 1 & $(6 \%)$ & 0 & $(0 \%)$ & 3 & $(18 \%)$ \\
\hline Progressive conduction defect & 21 & 2 & $(10 \%)$ & 1 & $(5 \%)$ & 1 & $(5 \%)$ & 1 & $(5 \%)$ \\
\hline
\end{tabular}

LAD, left axis deviation; AV, atrioventricular.

left axis deviation and the other right bundlebranch block.

Postoperative complete heart block and ventricular arrhythmia were not found in any of the patients who died suddenly. During follow-up, one patient had supraventricular tachycardia and another frequent ventricular extrasystoles, but no cases of complete heart block or bradycardia were documented.

\section{AMBULATORY MONITORING}

\section{Supraventricular arrhythmias}

Thirty-eight patients $(56 \%)$ had atrial extrasystoles recorded on the 24-hour electrocardiogram. The total number of atrial extrasystoles ranged from one to 5184 in 24 hours. Only four patients $(5 \%$ ) had more than 1000 atrial extrasystoles in 24 hours, and two of these patients belonged to the group with progressive conduction disorders. A further four patients $(5 \%)$ had paroxysmal supraventricular tachycardia.

Thirteen patients $(18 \%)$ had evidence of sinus node dysfunction, with either periods of sinus arrest for longer than two seconds, sinus bradycardia less than 35 beats per minute, or sinuatrial block. Three of these 13 patients had progressive left axis shift on serial electrocardiograms.

Table 3 Arrhythmias and conduction defects in patients who died suddenly

\begin{tabular}{lllll}
\hline $\begin{array}{l}\text { Case } \\
\text { no. }\end{array}$ & $\begin{array}{l}\text { Postoperative } \\
\text { conduction } \\
\text { defect }\end{array}$ & $\begin{array}{l}\text { Follow-up } \\
\text { conduction } \\
\text { defect }\end{array}$ & $\begin{array}{l}\text { Postoperative } \\
\text { arrhythmia }\end{array}$ & $\begin{array}{l}\text { Late } \\
\text { arrhythmia }\end{array}$ \\
\hline 1 & RBBB & RBBB & - & - \\
2 & RBBB & RBBB & - & - \\
3 & RBBB & RBBB & - & $\begin{array}{l}\text { Supraventricu- } \\
\text { lar tachycardia }\end{array}$ \\
4 & RBBB & RBBB & - & - \\
5 & RBBB & RBBB +LAD & - & - \\
6 & RBBB & RBBB & - & Ventricular \\
$7 \star$ & RBBB & RBBB & - & extrasystoles \\
8 & RBBB + LAD & RBBB + LAD & - & - \\
9 & Normal & RBBB & Junctional & - \\
& & & tachycardia
\end{tabular}

LAD, left axis deviation; RBBB, right bundle-branch block.

*Operation performed at The Hospital for Sick Children, Great Ormond Street.

\section{Atrioventricular block}

The incidence of atrioventricular block during ambulatory monitoring is shown on Table 4. First degree heart block was noted throughout the 24hour period in three patients and occurred intermittently in a further three cases. Five of these six patients had right bundle-branch block with a normal QRS axis, and the remaining patient had progressive left axis deviation during follow-up. Second degree heart block and complete heart block were uncommon findings: transient atrioventricular dissociation, with a ventricular rate of 50 to $60 /$ minute, occurred in two patients, and both had right bundle-branch block and a normal QRS axis.

Table 4 Atrioventricular block detected during ambulatory monitoring in 74 patients

\begin{tabular}{llll}
\hline \multirow{2}{*}{ Heart block } & \multicolumn{3}{l}{ Conduction defect on electrocardiogram } \\
\cline { 2 - 4 } & $\begin{array}{l}R B B B \\
n o .=55\end{array}$ & $\begin{array}{l}R B B B+L A D \\
\text { no. }=4\end{array}$ & $\begin{array}{l}P C D \\
\text { no. }=15\end{array}$ \\
\hline Intermittent $1^{\circ}$ AVB & 2 & 0 & 1 \\
Stable $1^{\circ}$ AVB & 3 & 0 & 0 \\
$2^{\circ}$ AVB & 2 & 0 & 0 \\
$3^{\circ}$ AVB & 2 & 0 & 0 \\
\hline
\end{tabular}

AVB, atrioventricular block; PCD, progressive conduction defect; LAD, left axis deviation.

\section{Ventricular arrhythmias}

Fifty-seven patients $(77 \%)$ had ventricular extrasystoles, ranging from one to 10191 per 24 hours. Seventeen patients $(23 \%)$ had over 500 ventricular extrasystoles in 24 hours, 15 patients $(20 \%)$ had multiform ventricular extrasystoles, and 13 patients $(18 \%)$ had pairs of ventricular extrasystoles (couplets). Ventricular arrhythmias, of Lown grade 2 or greater, were found in 30 patients $(41 \%)$. Ventricular tachycardia (grade $4 \mathrm{~b}$ ) was not detected in any of the patients during 24-hour monitoring.

Table 5 shows the frequency and grade of ventricular ectopic activity detected during 24-hour monitoring in relation to the conduction pattern on the resting electrocardiogram. The incidence of grade 2,3 , or 4 ventricular arrhythmias in the group 
Table 5 Frequency and grade of ventricular ectopic activity during 24-hour monitoring in relation to electrocardiographic conduction pattern

\begin{tabular}{|c|c|c|c|c|c|c|c|c|c|c|c|c|}
\hline \multirow{3}{*}{ Conduction defect } & \multirow{3}{*}{$\begin{array}{l}\text { No. of } \\
\text { patients }\end{array}$} & \multirow{3}{*}{$\begin{array}{l}\text { Per cent of } \\
\text { patients } \\
\text { with } \\
\text { ventricular } \\
\text { extrasystoles }\end{array}$} & \multirow{2}{*}{\multicolumn{6}{|c|}{$\begin{array}{l}\text { Highest grade of ventricular } \\
\text { extrasystoles during } \\
24 \text { hours }(\%)\end{array}$}} & \multicolumn{4}{|c|}{ Per cent of patients with ventricular extrasystoles } \\
\hline & & & & & & & & & \multirow[t]{2}{*}{$\begin{array}{l}\text { Thirty } \\
\text { in any hour }\end{array}$} & \multirow[t]{2}{*}{$\begin{array}{l}\text { Total } \\
500 \text { to } 1000\end{array}$} & \multirow[t]{2}{*}{$\begin{array}{l}\text { Total }{ }^{\star} \\
>1000\end{array}$} & \multirow[t]{2}{*}{$\begin{array}{l}\text { Grade } \\
2,3, \text { or } 4\end{array}$} \\
\hline & & & 0 & 1 & 2 & 3 & $4 a$ & $4 b$ & & & & \\
\hline $\begin{array}{l}\text { RBBB } \\
\text { RBBB + postop LAD } \\
\text { PCD } \\
\text { Total group }\end{array}$ & $\begin{array}{r}55 \\
4 \\
15 \\
74\end{array}$ & $\begin{array}{l}76 \\
50 \\
87 \\
77\end{array}$ & $\begin{array}{l}24 \\
50 \\
13 \\
23\end{array}$ & $\begin{array}{r}46 \\
25 \\
7 \\
36\end{array}$ & $\begin{array}{r}2 \\
0 \\
20 \\
6\end{array}$ & $\begin{array}{r}14 \\
0 \\
33 \\
17\end{array}$ & $\begin{array}{l}14 \\
25 \\
27 \\
18\end{array}$ & $\begin{array}{l}0 \\
0 \\
0 \\
0\end{array}$ & $\begin{array}{l}13 \\
25 \\
33 \\
18\end{array}$ & $\begin{array}{r}11 \\
0 \\
20 \\
12\end{array}$ & $\begin{array}{r}5 \\
25 \\
27 \\
11\end{array}$ & $\begin{array}{l}30 \\
25 \\
80 \\
41\end{array}$ \\
\hline
\end{tabular}

PCD, progressive conduction defect; LAD, left axis deviation.

* These three categories and the ventricular extrasystole grades are not mutually exclusive.

of patients with progressive conduction defects was 80 per cent. This is significantly higher than the incidence found in the group with right bundlebranch block and no axis shift during follow-up (p $<0.01)$.

Symptoms, surgical technique, and postoperative haemodynamic data (in particular the presence of a residual ventricular septal defect or right ventricular outflow obstruction) were analysed. We were, however, unable to establish any symptom, haemodynamic measurement, or surgical factor as a predictor of conduction defects, late arrhythmias, or late sudden death.

\section{Discussion}

The overall incidence of late sudden death during a mean follow-up of 10 years was 4.6 per cent. This compares with reported incidences of 2.9 per cent $^{7}$ and 3.4 per cent ${ }^{1}$ over a similar period. Previous reports have attempted to identify risk factors for sudden death and to determine the antecedent mechanism. Several authors have suggested that the presence of right bundle-branch block and left axis deviation after correction of tetralogy of Fallot implies a poor long-term prognosis. ${ }^{2} 3$ Wolff et al. ${ }^{3}$ reported a series of 24 patients with right bundle-branch block and left axis deviation in which the incidence of sudden death was 12.5 per cent. The significance of this conduction disturbance, however, has been the subject of controversy. Cairns et al. ${ }^{4}$ reported no sudden deaths among 31 patients with postoperative right bundle-branch block and left axis deviation over a mean follow-up of 27 months. A favourable prognosis has also been found by Downing et al. ${ }^{5}$ and Steeg et al. ${ }^{10}$ In our study we are also unable to associate a poor prognosis with this conduction disturbance as only one of 17 patients with postoperative right bundle-branch block and left axis deviation has died suddenly. An important finding, however, was a group of 21 patients (11\%) with evidence of progression of conduction disturbance during long-term follow-up. These patients had either normal conduction or right bundle-branch block alone postoperatively, but developed left axis deviation or new right bundle-branch block between six months and six years after surgery. Though the difference was not statistically significant, sudden death or complete heart block occurred in 19 per cent of the patients with progressive conduction defects and in only 4 per cent with stable conduction pattern.

The disparity in reported prognosis for patients with postoperative right bundle-branch block and left axis deviation may result from the failure of the scalar electrocardiogram to distinguish between central and peripheral damage to the conducting system. Injury to the central portion of the right bundle may occur as a result of closure of the ventricular septal defect, ${ }^{11}$. while right bundlebranch block may result from damage to the distal right bundle caused by right ventriculotomy. ${ }^{12}$ Horowitz et al. ${ }^{13}$ using epicardial activation mapping, found that right bundle-branch block appeared after infundibular resection during transatrial repair of tetralogy of Fallot. Additional left axis deviation need not necessarily imply block of the anterior fascicle of the left bundle-branch. ${ }^{14}{ }^{15}$ Thus, patients with right bundle-branch block and left axis deviation are not likely to represent a homogeneous group. The anatomical location of the lesions in the patients with progressive conduction defects remains to be clarified by electrophysiological and pathological studies.

There is still debate about the nature of the arrhythmia responsible for late sudden death after correction of tetralogy of Fallot. Wolff et al. ${ }^{3}$ speculated that sudden death associated with right bundle-branch block and left axis deviation results from subsequent complete heart block. Moss et al. ${ }^{16}$ also reported late complete heart block after 
correction of tetralogy of Fallot and related its occurrence to perioperative complete heart block. Intracardiac electrophysiological studies have been performed to identify patients at risk from complete heart block. Gillette et al. ${ }^{6}$ found a prolonged HV interval in only one of eight patients with postoperative right bundle-branch block and left axis deviation, and they were unable to correlate either first degree block, prolonged $\mathrm{AH}$ or $\mathrm{HV}$ intervals with late complete heart block, or a poor prognosis. In our series there were only two cases of late complete heart block; both patients had progressive left axis deviation during follow-up with a normal postoperative QRS axis. Transient perioperative complete heart block occurred in 10 patients. Only one of these developed late complete heart block, and one other has died. Twenty-four hour monitoring has not disclosed a high incidence of unsuspected heart block associated with any electrocardiographic conduction defect.

Ventricular arrhythmia is an alternative mechanism for sudden death after correction of tetralogy of Fallot. Gillette et al. ${ }^{6}$ reported late sudden death in three of nine patients with ventricular extrasystoles on the resting electrocardiogram, none of whom had significant conduction disturbance during intracardiac electrophysiological study. Garson et al. ${ }^{1}$ in a series of 233 patients found ventricuiar extrasystoles on the electrocardiograms of all eight patients who died suddenly, with no evidence of complete heart block. James et al., ${ }^{8}$ Quattlebaum et al.,7 and Rosing et al. ${ }^{17}$ all considered ventricular arrhythmias to be a more important cause of sudden death than heart block. Our results have shown a high incidence $(41 \%)$ of significant ventricular arrhythmias (Lown grade 2 or above) on ambulatory monitoring. This incidence is considerably greater than that found in studies of comparable subjects without heart disease. ${ }^{18}$ These ventricular arrhythmias were significantly increased among patients with evidence of progressive conduction defects. Ventricular extrasystoles, in the presence of conduction block, may be particularly significant because of a greater potential for re-entry arrhythmias. Even ventricular extrasystoles which have features normally considered benign may be important and in Quattlebaum's series ${ }^{7}$ the ventricular extrasystoles associated with sudden death were unifocal, with late coupling. Garson et al. ${ }^{1}$ were able to correlate the occurrence of ventricular arrhythmias and sudden death with a raised right ventricular systolic pressure. We were, however, unable to relate the presence of arrhythmias or late sudden death to surgical technique or to any residual postoperative haemodynamic abnormality.

We cannot link the presence of ventricular arrhythmia with sudden death as none of our patients who underwent 24-hour monitoring has died. Several different mechanisms are probably responsible for late sudden death after correction of tetralogy of Fallot. Our results disclosed a high incidence of serious ventricular arrhythmia, particularly in patients with progressive conduction disease. As occult arrhythmia may be the cause of sudden death in tetralogy of Fallot, it is important to detect these patients; appropriate treatment remains to be defined.

We thank Professor J F Goodwin, Professor $\mathrm{H} \mathrm{H}$ Bentall, Mr W P Cleland, and Dr C M Oakley for allowing us to study their patients. Statistical advice was kindly provided by Ms A Petrie of the Royal Postgraduate Medical School.

\section{References}

1 Garson A Jr, Nihill MR, McNamara DG, Cooley DA. Status of the adult and adolescent after repair of tetralogy of Fallot. Circulation 1979; 59: 1232-40.

2 Kulbertus HE, Coyne JJ, Hallidie-Smith KA. Conduction disturbances before and after surgical closure of ventricular septal defect. Am Heart $\mathcal{F}$ 1969; 77: $123-31$.

3 Wolff GS, Rowland TW, Ellison RC. Surgically induced right bundle-branch block with left anterior hemiblock. An ominous sign in postoperative tetralogy of Fallot. Circulation 1972; 46: 587-95.

4 Cairns JA, Dobell ARC, Gibbons JE, Tessler I. Prognosis of right bundle branch-block and left anterior hemiblock after intracardial repair of tetralogy of Fallot. Am Heart $\mathcal{f} 1975$; 90: 549-54.

5 Downing JW Jr, Kaplan S, Bove KE. Postsurgical left anterior hemiblock and right bundle-branch block. Br Heart f 1972; 34: 263-70.

6 Gillette PC, Yeoman MA, Mullins CE, McNamara DG. Sudden death after repair of tetralogy of Fallot. Electrocardiographic and electrophysiologic abnormalities. Circulation 1977; 56: 566-71.

7 Quattlebaum TG, Varghese PJ, Neill CA, Donaghoo JS. Sudden death among postoperative patients with tetralogy of Fallot. A follow up study of 243 patients for an average of 12 years. Circulation 1976; 54: 289-93.

8 James FW, Kaplan S, Chou TC. Unexpected cardiac arrest in patients after surgical correction of tetralogy of Fallot. Circulation 1975; 52: 691-5.

9 Ryan M, Lown B, Horn H. Comparison of ventricular ectopic activity during 24-hour monitoring and exercise testing in patients with coronary heart disease. $N$ Engl f Med 1975; 292: 224-9.

10 Steeg CN, Krongrad E, Davachi F, Bowman FO Jr, Malm JR, Gersony WM. Postoperative left anterior hemiblock and right bundle branch block following repair of tetralogy of Fallot: clinical and etiologic consideration. Circulation 1975; 51: 1026-9. 
11 Titus JL, Daugherty GW, Kirklin JW, Edwards JE. Lesion of the atrioventricular conduction system after repair of ventricular septal defect: relation to heart block. Circulation 1963; 28: 82-8.

12 Gelband H, Waldo AL, Kaiser GA, Bowman FO Jr, Malm JR, Hoffman BF. Etiology of right bundlebranch block in patients undergoing total correction of tetralogy of Fallot. Circulation 1971; 44: 1022-33.

13 Horowitz LN, Simson MB, Spear JF, et al. The mechanism of apparent right bundle branch block after transatrial repair of tetralogy of Fallot. Circulation 1979; 59: 1241-52.

14 Krongrad E, Rosen MR, Merker C, Hoffman BF. Creation of counterclockwise superiorly orientated frontal plane loops (CCW-SOFPL) in isolated blood perfused canine hearts (abstract). Pediatr Res 1973; 7: 300 .

15 Watt TB Jr, Pruitt RD. Focal lesions in the canine bundle of His: their effects on ventricular excitation. Circ Res 1972; 31 : 531-45.

16 Moss AJ, Klyman G, Emmanouilides GC. Late onset complete heart block. Am $\mathcal{F}$ Cardiol 1972; 30: 884-7.

17 Rosing DR, Borer JS, Kent KM, et al. Long-term hemodynamic and electrocardiographic assessment following operative repair of tetralogy of Fallot. Circulation 1978; 58, suppl I: 209-17.

18 Brodsky M, Wu D, Denes P, Kanakis C, Rosen KM. Arrhythmias documented by 24 hour continuous electrocardiographic monitoring in 50 male medical students without apparent heart disease. $A m \mathcal{F}$ Cardiol 1977; 39: 390-5.

Requests for reprints to Dr J E Deanfield, Division of Cardiovascular Disease, Royal Postgraduate Medical School, Du Cane Road, London W12 0HS. 